\title{
The Pandemic Crisis as a Challenge for Economic Analysis and Policy
}

\author{
A. A. Shirov* \\ Institute for Economic Forecasting, Russian Academy of Sciences, Moscow, Russia \\ *e-mail: schirov-mse@yandex.ru \\ Received January 12, 2021; revised January 15, 2021; accepted January 18, 2021
}

\begin{abstract}
The article is devoted to the main directions of the development of economic analysis under the influence of a pandemic crisis. The key features of the pandemic crisis, the formation of economic dynamics in its course, and the main directions of the authorities' response to the deterioration of the medical situation are considered. A description of the main directions of economic analysis during a pandemic crisis is given and the reasons for overestimating or underestimating the forecast estimates made at the beginning of the crisis are assessed. The possibilities of interdisciplinary research aimed at improving the quality of the authorities' response to changes in the epidemiological situation are considered. The principles of separation of tasks of economic analysis are formulated in the framework of policy support during the coronavirus crisis.
\end{abstract}

Keywords: coronacrisis, economic analysis, economic policy, lockdown, GDP, intersectoral relations DOI: $10.1134 / \mathrm{S} 1075700721030138$

Features of economic dynamics and politics during a pandemic crisis. The economic upheavals that hit the world in 2020 were fundamentally of a special nature that is not characteristic of all the crises that humanity has faced in recent decades. First of all, it should be noted that this crisis was not directly related to the business cycle, but its depth was directly determined by the severity of the measures that were used by governments to counter the pandemic of the new coronavirus COVID-19.

Over time, doctors have accumulated more and more information about the new virus, how it spreads and the impact on human health. By March-April 2020 , a calm attitude towards what was happening was replaced by panic in both society and the ruling circles of most of the world's major economies.

To a large extent, these sentiments were reinforced by calculations based on a number of epidemiological models both abroad [1] and in Russia [2, 3]. Many experts agree that it was the apocalyptic figures of possible deaths from the new coronavirus infection that pushed the governments of different countries to introduce tough quarantine measures $\left(\right.$ lockdown $\left.^{1}\right)$.

The development of the pandemic and the introduction of strict quarantine measures have posed a number of new and rather difficult questions for economists. Let's try to identify the key ones.

\footnotetext{
${ }^{1}$ A lockdown is understood as a period of strict quarantine, during which nearly all economic activity stops and restrictions are introduced on the free movement of citizens.
}

1. How should the impact of a lockdown on economic dynamics be assessed within the annual cycle and for the year as a whole?

2. What are the highest priorities for assessing the effectiveness of government policies during a pandemic?

3. To what extent can interdisciplinary research contribute to building effective economic policies in the fight against the epidemic?

To begin with, let's try to outline how the decisions were made and their impact on the economy. The spread of coronavirus around the world began with the movement of infected citizens, so the main measures taken by the authorities at the first stage were restrictions on the free cross-border movement of people. From the point of view of afterthought, it can be stated that these actions were belated in most countries. However, they affected transport to one degree or another, which became the first sector of the economy to be affected globally. For example, according to ICAO, global passenger traffic in air transport in March 2020 decreased by $52.9 \%$ compared to the same month in 2019. The next affected segment was global trade, which experienced restrictions related to cross-border movement of goods. According to the WTO, the decline in world trade in goods in the second quarter of 2020 was $14.3 \%$. Finally, when it became clear that the pandemic could not be stopped solely by cross-border measures, it was time to restrict domestic economic activity [4]. 


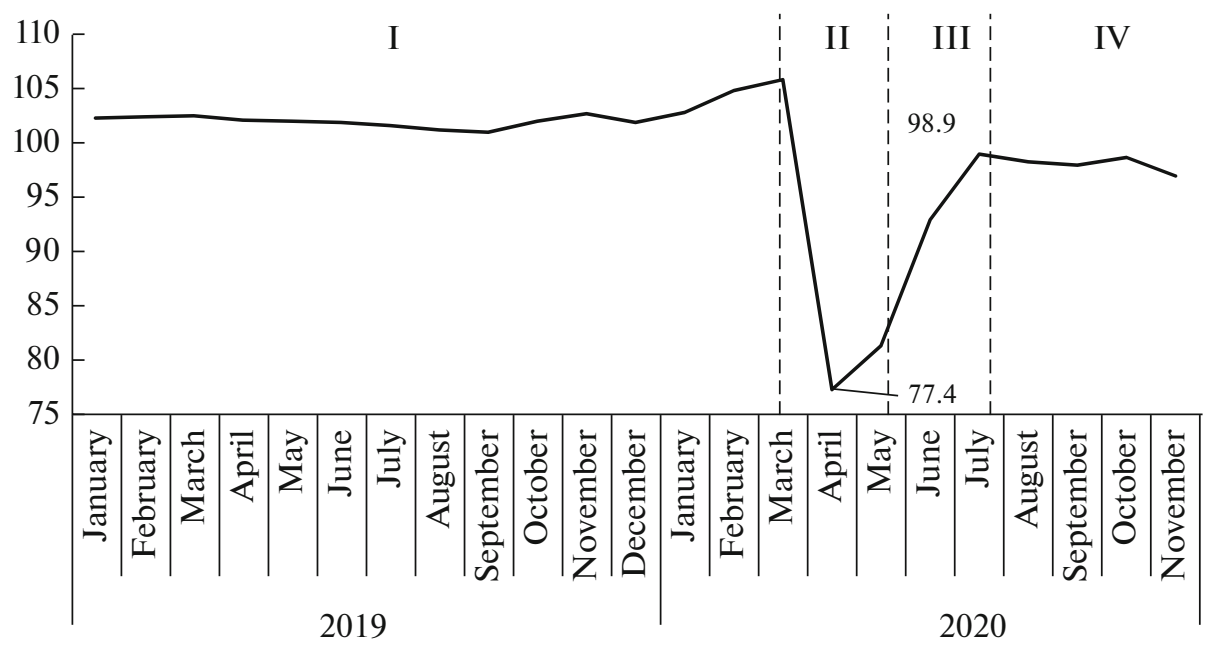

Fig. 1. Dynamics of retail turnover, growth rate versus the corresponding period of the previous year,\%. Source: Rosstat.

Let's try to outline the key features of the pandemic crisis. This will enable us to more effectively investigate its consequences and assess the effectiveness of economic policy measures. The following differences can be distinguished between a pandemic crisis and a classic cyclical recession:

1. There is no period of increasing crisis phenomena. A pandemic crisis in the economic field begins with the restrictions adopted by the authorities in relation to the activities of sectors of the economy (in the case of a lockdown, the shutdown of most production).

2. The duration and severity of the main phase of the crisis is determined by the period of restrictive measures and their composition.

3. Recovery from the crisis is accompanied by an explosive growth in demand, much stronger than in the case of an ordinary crisis. The longer the lockdown, the stronger this jump in demand.

4. The rest of the way out of the pandemic crisis is similar to that observed in the cyclical crisis and is determined by the balancing of demand, supply and prices at new levels.

The last point allows us to make the assumption that economic policy at the stage of overcoming the pandemic crisis may hardly differ in nature from actions within the framework of a classic cyclical crisis. Its action should be aimed at the fastest possible overcoming of the consequences of a contraction in demand and a decrease in household income.

Using the example of the dynamics of retail trade turnover (Fig. 1), one can trace the stages of the coronavirus crisis in the Russian economy. Note that until April 2020, there were no signs of a deterioration in demand. Yes, the pace of economic development could not be considered satisfactory, but no crisis manifestations were observed during this period (stage I, develop- ment within the framework of the classic business cycle).

The economic crisis began after the relevant decisions on self-isolation, the bulk of which fell on the last days of March 2020. As a result, for example, the decline in retail turnover in April compared to the same month in 2019 was already $22.6 \%$. A low level of demand persisted in May as well, against the background of the continuation of lockdown (stage II, acute phase of the pandemic crisis) [5].

The abolition of strict restrictions on movement and economic activity leads to a sharp surge in demand (stage III, implementation of deferred demand). This is primarily due to the fact that in the context of the closure of trade enterprises, the demand delayed for several months is realized within several weeks. For example, sales of passenger cars in April 2020 decreased to 39 thousand units (with an average monthly value of 128 thousand units for JanuaryMarch 2020). But already in June, sales amounted to 123 thousand units, and in July 142 thousand units, which is about 10 thousand more than in July 2019.

It should be borne in mind that deferred demand is concentrated not only among the population. Logistics difficulties lead to a reduction in producers' inventories, which recover as the economy opens up, supporting demand for intermediate products. Companies that were unable to fulfill regular orders due to restrictions are also completing their contracts, which contributes to an active recovery of production indicators.

The rapid rise in demand after the end of the quarantine could create the illusion of a quick recovery in economic activity among analysts and authorities. At the same time, this impulse is limited in time, and if it is not supported by additional measures of economic policy, the economy will reach a plateau, the dynamics 
of which will be provided by a lower-than-precrisis balance of supply and demand.

At the end of 2020, the Russian economy is showing a decline of $4 \%$, which is significantly better than most estimates noted at the beginning of the crisis. At the peak of the crisis, in the second quarter, the decline in GDP $(-8 \%)$ turned out to be significantly less than the values observed in the world's largest economies. There were several reasons for this. First, due to the artificial nature of the slowdown in economic activity, the severity of quarantine measures played an important role. In Russia, activities in agriculture, construction, the military-industrial complex, and basic raw material industries were relatively weakly limited. Second, the worst hit of the crisis fell on the nonproductive services sector, and its share in Russia is about 10 p.p. lower than in most developed economies in Europe. Thirdly, the raw material nature of Russian exports is a natural damper in the context of global crises since the demand for energy resources is decreasing significantly less than for final products. It is noteworthy that the physical dynamics of Russian exports in the second quarter, even despite the OPEC+ deal, showed a positive trend of $0.3 \%$. Fourth, the low parameters of consumer and investment demand in the period before the crisis naturally reduced the potential for economic recession.

Now let us dwell on the key features of the economic policy pursued during the coronavirus crisis. First of all, the anticrisis measures were based on actions aimed at preserving employment and incomes of the population. Families with children, officially employed employees of the affected sectors of the economy, and retirees received direct support. It should be noted that in this area the funds were delivered to the target groups quickly and efficiently. Indirect evidence of this is the positive dynamics of real wages and pensions. However, it was not possible to avoid a serious decline in real incomes. The incomes of those who are minimally dependent on the state have suffered significantly: entrepreneurs working in medium and small businesses, as well as those employed in the shadow sector of the economy [6]. Only a growing economy can support their income.

Another area of support was actions in relation to systemically important companies: subsidies, state guarantees and deferral of tax payments. An unexpectedly effective measure was to reduce insurance premiums for small and medium-sized businesses [7].

When choosing the tools to support the economy, the government acted rather cautiously with regard to the accumulated reserves. In particular, tools to stimulate demand were only partially involved, the funds of the National Welfare Fund (NWF) were barely used. At the same time, the nominal expenditures of the federal budget for eleven months of 2020 increased by more than a quarter in relation to the level of 2019. It seems that we are gradually getting a structure that allows financing the current budget through internal borrowing from banks, while there is an opportunity for their effective use of free liquidity and the development of the internal market for debt securities. Further active use of such a tool may require certain changes in monetary policy. In particular, with the exhaustion of free liquidity in the banking sector, loans from the central bank may become a source of purchase of bonds. In turn, the NWF can become a kind of "development budget," the funds of which are spent on macroeconomically significant long-term projects. This situation is also supported by a relatively loose monetary policy.

In general, it can be stated that the measures to support the economy, tested during the crisis of 20082009 , proved to be effective during the coronavirus crisis, with the only difference that in 2020 it was necessary to direct a significant amount of funds to support the medical sector. However, unlike the crisis a decade ago, significant resources were not required to support the banking system and systemically important enterprises in the payment of external debts.

At the exit from the crisis, measures to support the economy will be similar in many respects to those that are applied when exiting from market crises. At the same time, it is important to overcome the negative consequences of the coronavirus crisis as soon as possible in order to switch to measures to ensure the sustainability of the country's long-term economic development [8].

Approaches to the Analysis of Economic Dynamics during the Coronacrisis. The main problem of economic analysis during the coronavirus crisis was the inability to substantiate its onset using traditional economic forecasting tools used by experts around the world. It is hardly possible to create a model that would be able to describe both the origin of the epidemic and its impact on the development of the economy.

In this regard, the key analytical tasks during a pandemic should be associated with the accompaniment of economic policy.

As practice has shown, one of the most important areas of analysis during a pandemic crisis is to assess the potential recession both in the economy as a whole and in the context of individual types of economic activity. To do this, at the first stage, the decline in the month of hard lockdown was estimated, and then, assuming its duration, the possible dynamics by year were estimated (Table 1).

Having estimates of the dynamics of the decline in activity for certain types of economic activity, one can proceed to estimates of the total change in the parameters of gross output within the framework of a year, within which there was a pandemic crisis with a tough lockdown.

It should be noted that the duration of the lockdown can be estimated not only using medical calculations, but also based on the point of unacceptable economic damage-such a moment when the amount 
Table 1. Assessment of monthly and annual dynamics by type of economic activity

\begin{tabular}{|c|c|c|}
\hline \multirow[b]{2}{*}{ Economic activity } & \multicolumn{2}{|c|}{ Decline in demand } \\
\hline & $\begin{array}{c}\text { per month of hard lockdown } \\
\text { (year on year), } \%\end{array}$ & $\begin{array}{l}\text { per year with a lockdown duration } \\
\text { of } 2 \text { months. (year on year), } \%\end{array}$ \\
\hline Textile production & -50 & -8 \\
\hline Clothing; fur & -50 & -8 \\
\hline Leather and leather goods & -50 & -8 \\
\hline Coke oven products and petroleum products & -30 & -5 \\
\hline Motor vehicles, trailers and semi-trailers & -70 & -12 \\
\hline $\begin{array}{l}\text { Other vehicles and equipment, other mechanical engineer- } \\
\text { ing and petrochemical products }\end{array}$ & -30 & -5 \\
\hline Furniture; other manufactured goods not elsewhere classified & -50 & -8 \\
\hline Electricity, gas, steam and hot water & -10 & -2 \\
\hline Construction works & -50 & -8 \\
\hline Wholesale trade & -50 & -8 \\
\hline Retail trade & -50 & -8 \\
\hline Hotel and restaurant & -70 & -12 \\
\hline Land transport and pipeline transportation & -50 & -9 \\
\hline Water transport & -70 & -12 \\
\hline Air and space transport & -70 & -12 \\
\hline $\begin{array}{l}\text { Transport auxiliary and additional services; travel agency } \\
\text { services }\end{array}$ & -90 & -16 \\
\hline Services related to real estate & -70 & -11 \\
\hline Other services related to business & -50 & -9 \\
\hline Education & -20 & -3 \\
\hline Recreation, entertainment, culture and sports & -70 & -12 \\
\hline
\end{tabular}

Source: calculations of IEF RAS.

of funds to counter the economic consequences of the crisis will become unacceptable in terms of the ratio of the allocated funds and the available state capabilities. According to the Laboratory for Macrofinancial Research and Forecasting of the Institute of National Economic of the Russian Academy of Sciences, the point of unacceptable damage occurred after 2-2.5 months of hard lockdown. It was determined by the fact that in the period up to two months. the banking system can, due to free liquidity, fend off the growth of overdue debt. In the future, the continued growth of bad debts will require substantial support from the Central Bank [9]. At the same time, the scale of such support could exceed the anticrisis package developed by the Government of the Russian Federation.

Estimates of a possible recession for certain types of economic activity allow calculations of a decline in production taking into account the full effects (Fig. 2). For this, it is advisable to use the methodology for assessing the multiplier effects using input-output tables [10].
It can be noted that construction is among the leaders in the decline, taking into account direct and indirect effects. In reality, at the end of 2020, the construction industry showed near-zero dynamics. It is worth recalling that in 2009 the decline in construction activity was $13.2 \%$. And this is natural, since construction depends, firstly, on the economic activity of all sectors of the economy and their investments in investment activities, and secondly, on the incomes of the population, which affect the demand for housing.

The reason for the more favorable dynamics in construction in 2020 was the policy to support this sector of the economy through both the continuation of large investment projects, including within the framework of national projects, and support for the construction of social facilities and demand for housing by introducing a preferential rate on mortgage loans. As a result, housing commissioning in 2020 exceeded the same indicators for the previous year.

However, in general, the estimates of the decline in production by type of activity reflected the actual situation in the economy, and the very methodology for 


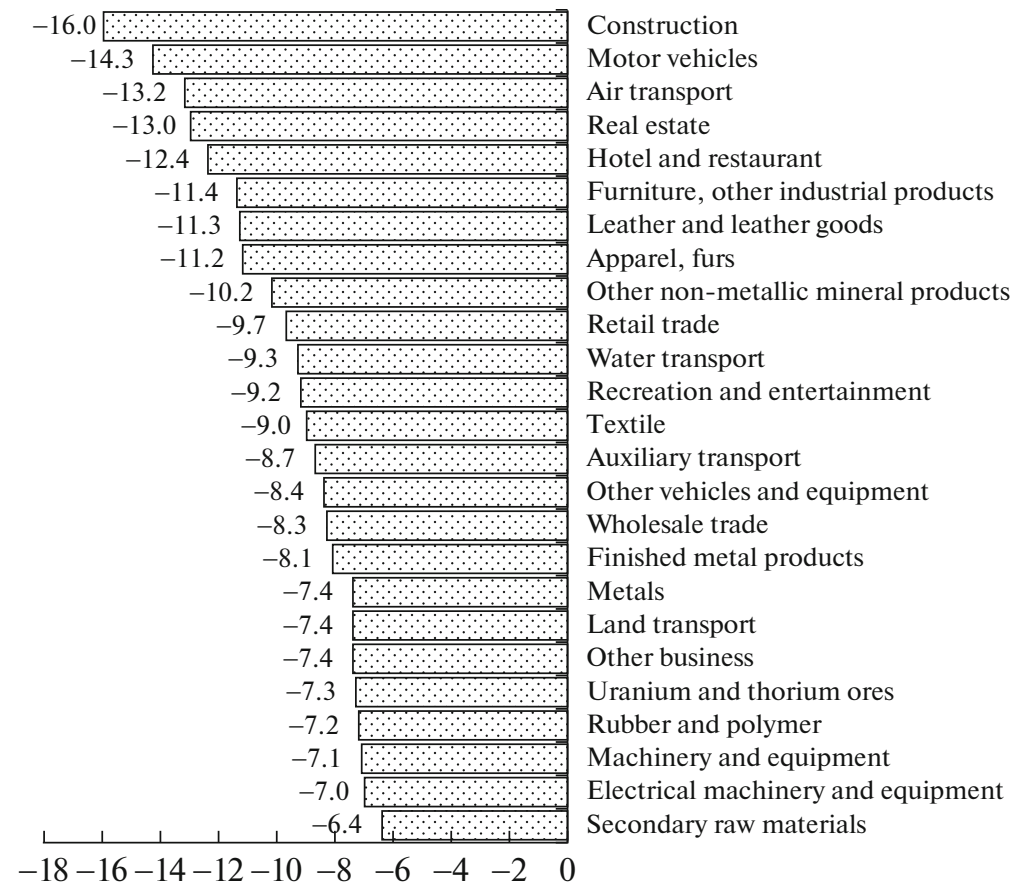

Fig. 2. Dynamics of output in 2020 by type of activity with a decline of more than 6\%, calculations as of March 30, 2020. Source: calculations of IEF RAS.

calculating them made it possible to flexibly respond to new data on quarantine measures in certain types of activity.

Additional opportunities provided by the inputoutput methodology are estimates of changes in employment for certain parameters of changes in output. Since such calculations are based on incremental labor intensity, they cannot be taken as direct estimates of changes in employment. In reality, the labor market is less flexible, both due to the supportive actions of the state and the behavior of entrepreneurs who understand that crises are over, and it is very difficult to find qualified workers. Rather, these are estimates of how many people are employed in certain sectors are in danger of being fired.

According to the data in Fig. 3, those employed in the service sector were the most under the threat of dismissal; it was to them that social support measures were addressed in the second quarter of 2020.

One of the conclusions obtained in the process of calculating possible changes in production and employment parameters in the context of the 2020 crisis is that the official input-output tables formed by Rosstat fairly correctly reflect the system of intersectoral relations that has actually developed in the Russian economy. This thesis is supported by calculations of interaction at the level of individual companies and corporations from various sectors of the economy.

It should also be mentioned that with a certain setting, the input-output methodology has been suc- cessfully applied for similar calculations at the level of regions and even individual large municipalities. To do this, there were enough data on the spatial structure of production and employment, which later served as the basis for adjusting the calculations at the country and regional levels.

The next area of economic analysis during the coronavirus crisis was the assessment of the effectiveness of various areas of economic policy. It is clear that in conditions of countering the negative consequences of the crisis, a wide range of measures to support the economy are applied, but it is also important to assess their possible impact not only on individual sectors, but also on the economy as a whole (Fig. 4).

As expected, banking support tools have the greatest effect, which, due to leverage, can provide up to 6.1 rubles for each ruble spent in the case of support for lending to the population and up to 4.6 rubles for each ruble of export credit support. However, it is clear that during the crisis, lending support is extremely limited. First of all, because both enterprises and the population are experiencing significant financial problems that do not make it possible to effectively use debt financing, even with state support. At the same time, it can be said that actions to support housing mortgages played a significant positive role in the formation of GDP in 2020.

Direct subsidies to support business sustainability are highly effective in times of crisis. Such subsidies have a high multiplier, not only because they help support production activities, but also save the business. 


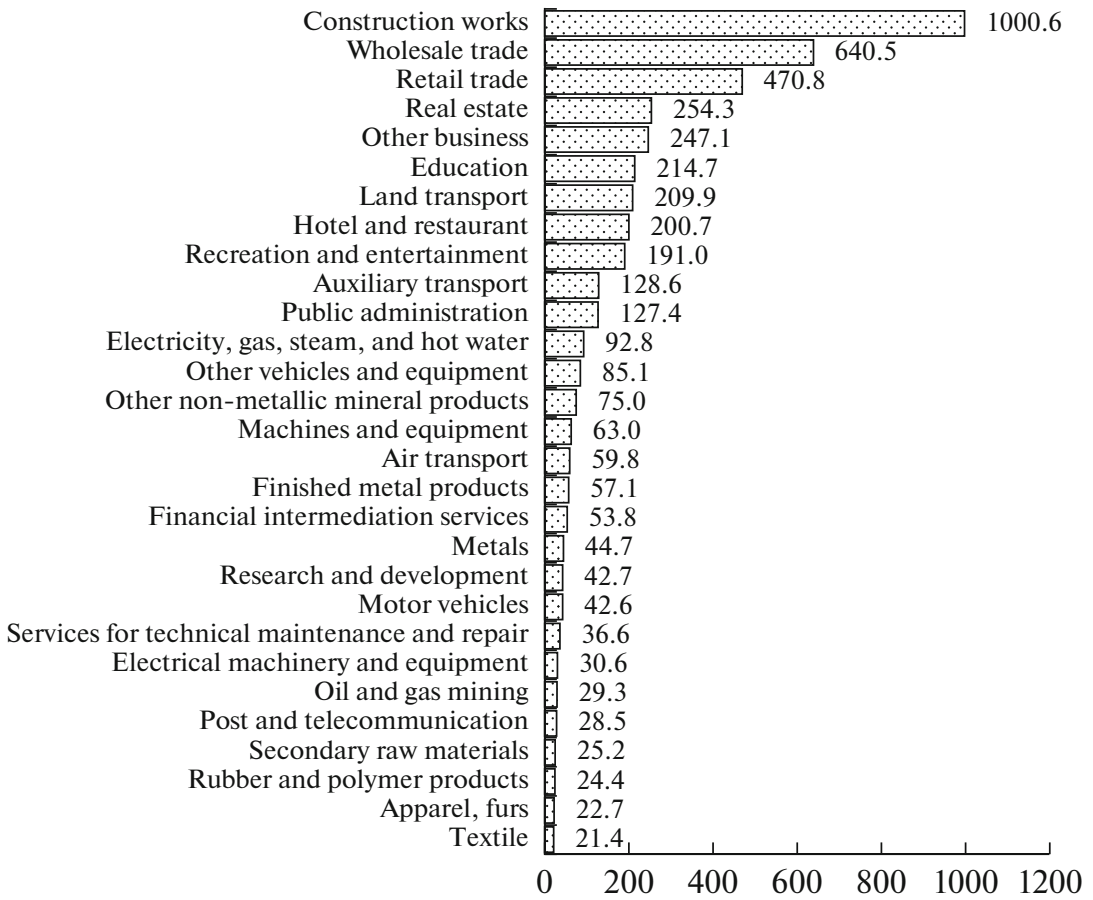

Fig. 3. Activities with the greatest potential for employment reduction in 2020, thousand people, calculations as of March $30,2020$. Source: calculations of IEF RAS.

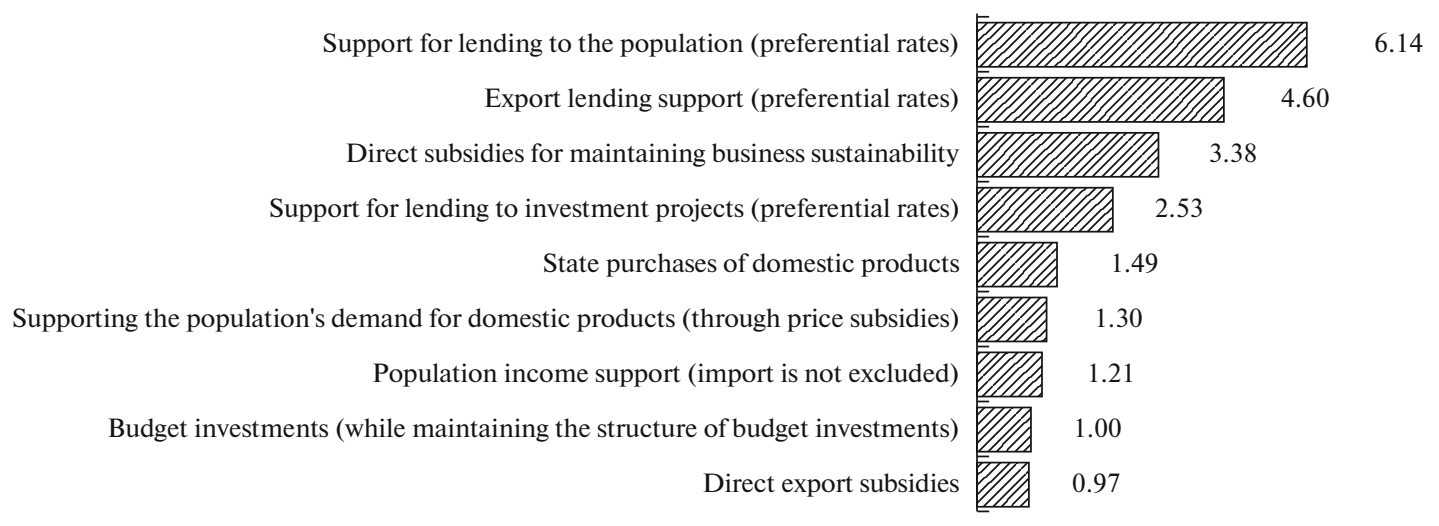

Fig. 4. Multipliers per GDP depending on various measures to support the economy (increase in BBB by 1 ruble increase in support measures) in 2020.

Source: calculations of IEF RAS.

In this regard, each ruble of such support, according to our estimates, generates up to 3.4 rubles of additional added value.

Support for lending to investment projects by subsidizing rates has a relatively lower multiplier (2.5 rubles of additional GDP growth per 1 ruble of increase in spending in this direction) due to the high share of imports in the structure of financing investment projects, in addition, the effects of such a support measure, unlike consumer lending, they can be stretched over time. Nevertheless, the large volume of funds that can be effectively used in this area, and their positive impact on the medium-term potential for economic growth, make subsidizing consumer loan rates one of the key areas of anticrisis policy.

The tool of public procurement has a sufficiently high multiplier, which allows supporting the financial and economic condition of enterprises by increasing government demand. In addition, this measure can accelerate the renewal of machinery and equipment in the social sphere and the public administration sector. 

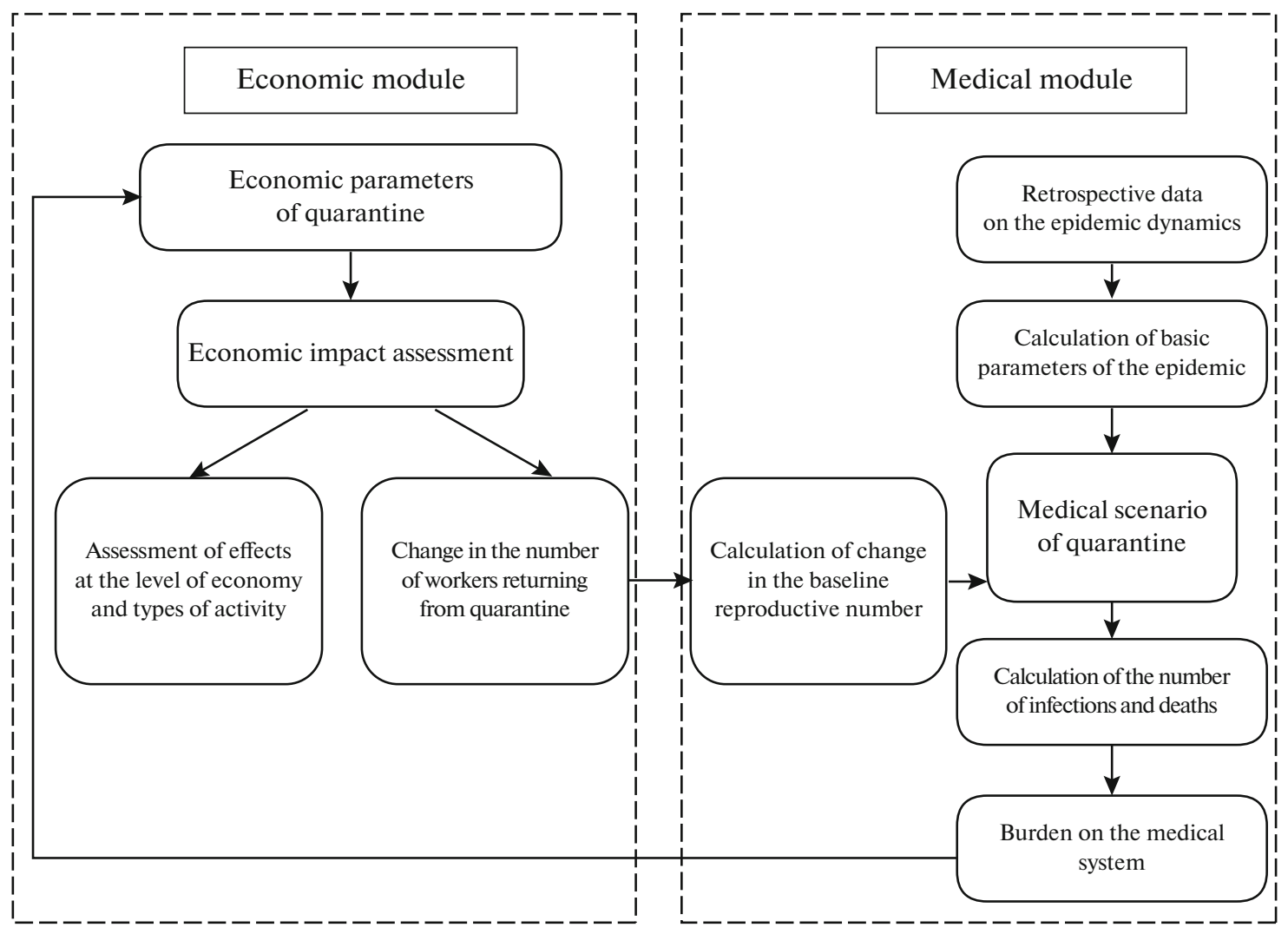

Fig. 5. Scheme of interaction between economic and medical settlement blocks.

Measures of direct support of the population through price subsidies or direct payments also have relatively low multipliers, but they have a large capacity, i.e., with a relatively lower multiplier, the macroeconomic effect can be very significant due to the possibility of using large amounts of support. At the same time, subsidizing prices for certain types of products has a greater multiplier than simple, unconditional support of the population, since in the second case, a significant part of the funds can be used to purchase imported products.

The smallest multiplier of all those considered has direct export support, which, in the context of the crisis, according to our estimates, will be insufficiently effective in terms of generating additional income in the economy.

Interdisciplinary Research and Conclusions for Economic Policy. The pandemic of the new coronavirus COVID-19, along with the dire social and economic consequences, has become a factor in uniting the scientific community in the search for the most effective solutions that can mitigate the consequences of the crisis and enable the authorities to adequately respond to the changing situation in the medical field and the economy.

One of the directions was the combination of calculations within the framework of economic and med- ical models. An approximate diagram of such a calculation system is shown in Fig. 5. Its peculiarity lies in the fact that the economic and medical blocks are linked through two channels. The first, the most important, relates the change in the number of workers being removed from quarantine by type of activity with a change in the base reproductive number [11], which directly affects the number of cases.

Most medical models use the change in the basic reproductive number as the main factor, which is directly related to the level of economic activity, and therefore, can be linked to economic dynamics by type of activity.

The second area of interaction is the burden on the medical system, which increases as the number of cases increases. Accordingly, knowing the maximum capacity of the number of beds, it is possible to assess the need to extend quarantine measures in relation to certain types of economic activity.

The combination of medical and economic analysis and forecasting methods is a very promising area of interdisciplinary research that can answer the question of the priority of actions in a pandemic, improve the efficiency of managing the economy and the health care system. At the same time, there are serious problems in this area of research. Let us try to list the main ones. 


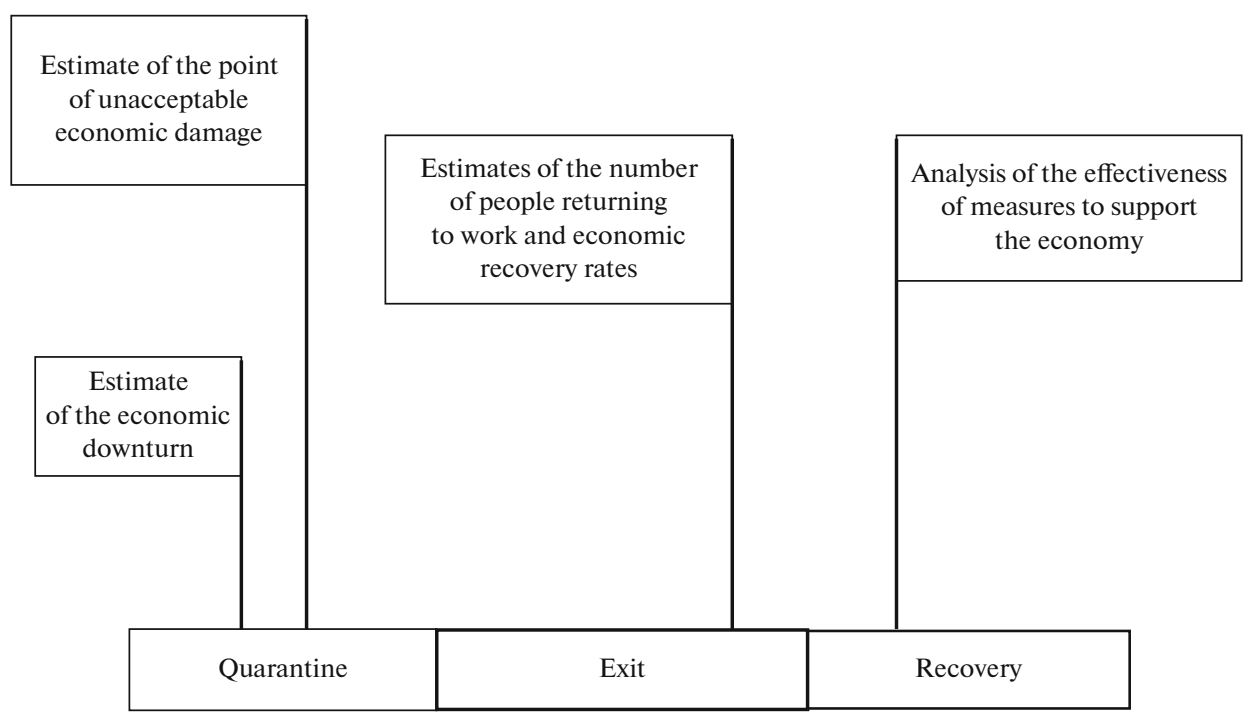

Fig. 6. Separation of directions of economic analysis during the pandemic crisis.

1. Medical models are high frequency, i.e., the forecast is given with a step per day, less often a week. Economic models, as a rule, operate with monthly, quarterly and annual statistics.

2. Epidemiological models are highly dependent on the quality of the data, which are subject to constant revision due to changes in accounting parameters, the number of tests and a number of other factors. As a result, the forecast estimates are constantly revised; it would be more correct to say that the models themselves change with a high frequency.

3. The most qualitative pandemic models use a multiagent approach, when the population is divided into separate groups, while economic models operate mainly on the number of employees by type of activity. As a result, medical calculations do not take into account the different characteristics of contact among workers employed in various sectors of the economy.

All the problems described complicate the interaction of medical and economic models, but do not make such interdisciplinary calculations inapplicable in practice. In fact, such calculations can be an important argument when deciding whether to tighten or relax the restrictions regime. One should only understand the limitations that exist in this kind of model construction.

Another element of interdisciplinary research in this area can be the connection to the system of analysis of a number of characteristics of the psychological state of society in relation to the actions of the authorities to counter the pandemic. As a number of studies show, the reaction of society to a pandemic and quarantine measures can have a long-term negative character, preventing the formation of a positive economic agenda in the period after the end of the crisis [12]. Under these conditions, an important aspect is the task of assessing the change in inequality as a result of the pandemic crisis and its impact on social stability in society [13].

Conclusions. The pandemic of the new coronavirus has led to the development of new directions of economic analysis and a number of interdisciplinary studies. In general, to date, key areas of economic analysis have been created that can increase the effectiveness of measures in the field of economic policy aimed at minimizing the negative consequences of the pandemic crisis.

From the point of view of the separation of the focus of attention to various aspects of the crisis, the following stages can be distinguished (Fig. 6):

-During the quarantine period, the main task of economic analysis is to assess the possible decline in economic activity, taking into account the duration of quarantine measures.

-The calculation of the point of unacceptable economic damage at which the economic consequences of the crisis in their scale begin to overlap the losses of a sociomedical nature can be important for assessing the duration of quarantine.

-During the period of weakening of quarantine measures by type of activity, it is important to assess the number of citizens returning to work and the impact of this factor on the incidence and burden on the health care system.

-During the period of economic recovery, important attention should be paid to assessing the effectiveness of anticrisis policy measures in order to overcome the negative consequences of the crisis as quickly as possible.

The nature of the pandemic crisis and the authorities' response to it suggest that the most effective methods of economic analysis in this case can be instruments of macrostructural analysis and forecast- 
ing, in particular, calculations based on the use of input-output methodology. At the same time, the use of aggregated macroeconomic calculations is limited in its capabilities due to the striking structural features of the crisis caused by different approaches to limiting economic activity depending on the type of economic activity.

For a more effective use of an interdisciplinary approach to the analysis of a pandemic, it is necessary to develop a methodology for approximating the principles of modeling at the medical and economic levels, creating unified principles for assessing the medical and economic situation at various stages of the crisis development.

\section{ACKNOWLEDGMENTS}

The author is grateful to D. A. Polzikov and D. M. Ksenofontov for their help and useful advices in writing this article.

\section{REFERENCES}

1. D. Adam, "Special report: The simulations driving the world's response to COVID-19," Nature 580, 316-318 (2020).

2. V. L. Makarov, A. R. Bakhtizin, E. D. Sushko, and A. F. Ageeva, "Modeling the COVID-19 epidemic: Advantages of an agent-based approach," Ekon. Sots. Peremeny: Fakty, Tendentsii, Prognoz 13 (4), 58-73 (2020).

3. D. M. Ksenofontov, "Scenario modeling of the epidemiological effects of economic policy," in Institute of Economic Forecasting, Russian Academy of Sciences: Scientific Proceedings (MAKS Press, Moscow, 2020), pp. 242-265 [in Russian].

4. Baker McKenzie: Supply Chains Reimagined: Recovery and Renewal in Asia Pacific and Beyond. https://www.bakermckenzie.com/-/media/files/insight/ publications/2020/08/supply-chains-reimagined_17-aug. pdf?la=en.

5. N. V. Akindinova, M. Dombrovski, A. A. Shirov, D. R. Belousov, I. B. Voskoboinikov, and E. T. Gurvich, "Prospects for the recovery of economic growth in Russia (based on the materials of the Round Table in the framework of the XXI April International Scientific Conference of the National Research University Higher School of Economics)," Vopr. Ekon., No. 7, 5-50 (2020).

6. RANEPA: "Society and the Pandemic: Lessons from the Fight against the COVID-19 Pandemic in Russia." https://www.iep.ru/files/text/other/COVID.pdf.

7. Stolypin Institute for the Economics of Growth. The Transformation of the Economic Model during the COVID-19 Pandemic in the World and Russia's Experience in Reducing Insurance Premiums for SMEs as a Key Step towards Economic Recovery. https://stolypin. institute/institute/transformatsiya-ekonomicheskoymodeli-v-period-pandemii-covid-19-v-mire-i-opytrossii-po-snizheniyu-strahovyh-vznosov-dlya-msp -kakklyuchevoy-shag-na-puti-k-vosstanovleniyu-ekonomiki/.

8. Institute of Economics of the Russian Academy of Sciences: "Proposals for Measures in the Field of Economic and Social Life of the Country after the End of the Active Phase of the Fight against Coronavirus." https://inecon.org/docs/2020/publications/Report_IE\% 20RAS_20200526.pdf.

9. M. Yu. Golovnin and S. A. Nikitina, "Channels of the impact of the COVID-19 pandemic on Russia's economy," Vestn. Inst. Ekon. Ross. Akad. Nauk, No. 5, 9-23 (2020).

10. A. R. Sayapova and A. A. Shirov, Fundamentals of the Input-Output Method: Handbook (MAKS Press, Moscow, 2019) [in Russian].

11. K. Linka, M. Peirlinck, and E. Kuhl, "The reproduction number of COVID-19 and its correlation with public health interventions," Comput. Mech. 66, 10351050 (2020). https://doi.org/10.1007/s00466-020-01880-8

12. T. A. Nestik, "Psychological consequences of a pandemic and resources of viability in the context of global risks," in Globalistics-2020: Global Problems and the Future of Mankind. Proc. Int. Sci. Congress (Moscow, 2020), pp. 808-813 [in Russian].

13. F. Ahmed, N. Ahmed, C. Pissarides, and J. Stiglitz, "Why inequality could spread COVID19," Lancet Public Health 5 (2), E240 (2020). Accessed September 20, 2020.

https://doi.org/10.1016/ S2468-2667(20)30085-2 (Accessed September 20, 2020) 